\title{
Avaliação da remoção de saxitoxinas por meio de técnicas de tratamento das águas de abastecimento
}

\section{Saxitoxins removal evaluation by means of the drinking-water treatment processes}

\section{Mônica Viana-Veronezi}

Engenheira Civil e Mestre em Saneamento, Meio Ambiente e Recursos Hídricos pela Universidade Federal de Minas Gerais (UFMG). Engenheira da Usinas Siderúrgicas de Minas Gerais S/A (Usiminas)

\begin{abstract}
Alessandra Giani
Bióloga pela UFMG. Mestre em Ecologia pela Universidade de Brasília (UnB). Doutora em Hidrobiologia (Universidade de Konstanz, Alemanha). Pós-doutorado pela Universidade de Quebec (Canadá). Pesquisadora do Conselho Nacional de Desenvolvimento Científico e Tecnológico (CNPq). Professora-associada do Departamento de Botânica da UFMG
\end{abstract}

Cristiane da Silva Melo

Acadêmica do quarto ano de Farmácia da UFMG. Bolsista de Iniciação Científica do CNPq

Lenora Ludolf Gomes

Bióloga. Mestre em Microbiologia pela UFMG. Doutora em Saneamento, Meio Ambiente e Recursos Hídricos pela UFMG

\section{Marcelo Libânio}

Engenheiro Civil. Mestre em Engenharia Sanitária pela UFMG. Doutor em Hidráulica e Saneamento pela Universidade de São Paulo (USP). Pós-doutorado pela Universidade de Alberta (Canadá). Pesquisador do CNPq e da Fundação de Amparo à Pesquisa do Estado de Minas Gerais (Fapemig). Professor-associado do Departamento de Engenharia Hidráulica e Recursos Hídricos da UFMG

\begin{abstract}
Resumo
O objetivo do trabalho é avaliar a eficiência da adsorção com carvão ativado em pó (CAP) e da cloração de cálcio na remoção de saxitoxinas. As saxitoxinas dispersas em água destilada foram produzidas por meio da extração de células viáveis de cianobactérias da espécie Cylindrospermopsis raciborskii. Os ensaios foram realizados em equipamento de jar test adaptado e empregando-se três tipos de CAP e hipoclorito de cálcio. Os tempos de detenção aplicados foram de duas horas para adsorção e 30 e 60 minutos para oxidação. Os resultados evidenciaram que a eficiência de remoção, para a adsorção, está intrinsecamente relacionada ao tipo de carvão e à dosagem empregada, obtendo maior eficiência para o CAP de madeira. Para oxidação, os dois tempos de contato e as dosagens avaliadas apresentaram eficiência praticamente constante, da ordem de 80\%, atendendo ao estabelecido pela Portaria 518.
\end{abstract}

Palavras-chave: saxitoxinas; cianotoxinas; adsorção; oxidação; tratamento de água

\begin{abstract}
This paper focuses on the evaluation of the saxitoxins removal by means of adsorption and oxidation. These toxins were produced through extraction of viable cells from cyanobacteria Cylindrospermopsis raciborskii. The tests were carried out in the batch scale with three different powdered activated carbons and calcium hypochlorite. The detention times were two hours for adsorption, and 30 and 60 minutes for oxidation tests. The results pointed out that the type and dosage of carbon are strongly related, and the wood carbon presented higher efficiency. The oxidation efficiency was approximately $80 \%$ for both evaluated detention times and distinct dosages, keeping practically constant for all tests according to the limit established by the Brazilian Drinking-water Legislation 518
\end{abstract}

Keywords: saxitoxins; cyanotoxins; adsorption; oxidation; water treatment. 


\section{Introdução}

As algas e cianobactérias exibem nítida ubiquidade nas águas superficiais, sendo presentes em lagos, reservatórios e cursos d'água, respondendo por meio da fotossíntese por parcela significativa da concentração de oxigênio dissolvido do meio aquático. A interferência na potabilização das águas descortina-se em várias perspectivas de acordo com o(s) grupo(s) predominante(s). Usualmente ocorre o aumento do consumo de produtos químicos empregados na coagulação, a redução da sedimentabilidade dos flocos e das carreiras de filtração, a elevação da demanda de cloro na desinfecção, com maior possibilidade de formação de trihalometanos ocasionando maiores riscos à saúde humana.

Em contexto similar, compostos orgânicos excretados por algumas espécies de algas e, principalmente, cianobactérias podem conferir odor e sabor e, em maiores concentrações, toxicidade às águas. Segundo o seu modo de ação, as toxinas produzidas por cianobactérias podem ser divididas nos seguintes grupos: hepatotoxinas, neurotoxinas e toxinas irritantes da pele (endotoxinas). As cianotoxinas são produtos do metabolismo secundário de cianobactérias, constituindo um grande grupo de toxinas naturais, podendo apresentar estrutura química e propriedades toxicológicas diversas (SIVONEN; JONES, 1999). Algumas dúvidas ainda persistem em relação à possível vantagem adaptativa na produção de cianotoxinas pelas cianobactérias. A hipótese mais aceita é a de que estes compostos tóxicos tenham função de defesa, como a dos anti-herbívoros produzidos por algumas plantas, que inibem a ação de predadores ou de algas competidoras (CARMICHAEL, 1992).

Às cianobactérias tóxicas reporta-se a maioria dos casos de intoxicações envolvendo ficotoxinas de águas doces ou marinhas. Tais intoxicações em humanos podem ocorrer pelo contato com a água contendo células tóxicas, pelo consumo de peixes de locais contaminados e/ou de água contaminada de reservatórios de abastecimento público. A ingestão de água contaminada por cianotoxinas pode acarretar distúrbios orgânicos de distintas naturezas. Em caso de acesso direto à corrente sanguínea a sua atuação é geralmente fatal, como demonstrou o conhecido caso dos pacientes de uma clínica de hemodiálise na cidade de Caruaru, Pernambuco em 1996.

As saxitoxinas, foco desta pesquisa, são constituídas por um grupo de alcaloides carbamatos que podem ser não-sulfatados (saxitoxina, neosaxitoxina), como um único grupamento sulfatado (goniautoxina), ou por dois sulfatos (C-toxina). Constituem-se na realidade um grupo de alcaloides neurotóxicos também conhecidos como "toxinas paralisantes de mariscos" (toxinas do tipo PSP - Parallytic Shellfish Poisoning), tendo sido primeiramente isoladas em dinoflagelados marinhos, responsáveis pela ocorrência de marés vermelhas. Estas toxinas são produzidas também por cianobactérias dos gêneros Aphanizomenon, Anabaena, Lyngbya e Cylindrospermopsis (SIVONEN; JONES, 1999).
As toxinas paralisantes interferem na comunicação entre os neurônios e as células musculares. As PSP inibem a condução nervosa por bloqueio dos canais de sódio, afetando a permeabilidade ao potássio ou à resistência das membranas. A toxicidade desse grupo é bastante variável, sendo as saxitoxinas as mais potentes. $\mathrm{A} \mathrm{DL}_{50}$ (dose letal intraperitonial em 50\% dos camundongos) para saxitoxinas purificada é de $10 \mu \mathrm{g} / \mathrm{kg}$ de peso corpóreo, enquanto que por consumo oral a $\mathrm{DL}_{50}$ é de aproximadamente $263 \mu \mathrm{g} / \mathrm{kg}$ de peso corpóreo (CHORUS; BARTRAM, 1999).

O histórico de intoxicações por cianotoxinas concorreu para inserção de cianobactérias, à época de forma inédita em relação aos padrões internacionais, no padrão de potabilidade estabelecido pela Portaria 518. Entre os parâmetros orgânicos contemplados, destaca-

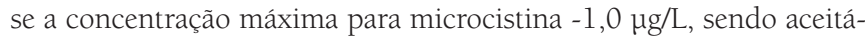
vel $10 \mu \mathrm{g} / \mathrm{L}$ em até três amostras no período de 12 meses, hepatotoxina produzida por algumas espécies de cianobactérias. Há também a recomendação da determinação de cilindrospermopsina e saxitoxina, com concentrações máximas de 15 e $3 \mu \mathrm{g} / \mathrm{L}$ de equivalentes saxitoxina/L (equivalentes STX/L), respectivamente.

Por fim, a Portaria 518 enfatiza também que o monitoramento das cianobactérias na água bruta deverá ser mensal quando o número de células for menor que 10.000 células/mL e semanal se superior. Caso o número de cianobactérias na água bruta exceder 20.000 células/mL, o monitoramento deverá se estender para o efluente da estação de tratamento, entrada de clínicas de hemodiálise e indústrias de injetáveis. Esta ampliação do monitoramento torna-se dispensável caso os bioensaios com camundongos atestem a ausência de toxicidade da cianotoxina (BRASIL, 2004). Outras cianotoxinas não foram inseridas pela inexistência de técnicas de detecção padronizadas e pela necessidade de informações mais consolidadas.

\section{Remoção de cianotoxinas no tratamento de água}

Há evidências que as tecnologias de tratamento usuais; envolvendo a coagulação química, floculação, sedimentação ou flotação, e filtração, não apresentam eficiência significativa na remoção de cianotoxinas dissolvidas na água. Tal fato, provavelmente, ocorra porque os coagulantes usualmente empregados são ineficazes na desestabilização e precipitação desses compostos, não sendo possível a separação das cianotoxinas nas etapas seguintes da potabilização (Chorus; Bartram, 1999). O controle da floração de algas pode viabilizar-se por meio da pré-cloração ou da aplicação de algicidas, tais como compostos de cobre (sulfato de cobre em maior escala) e permanganato de potássio. Também são usados em menor frequência, compostos de prata, sais orgânicos de zinco, ozônio, solventes aromáticos e peróxido de hidrogênio (água oxigenada). Todavia, nestas circunstâncias, além de possíveis impactos no ecossistema aquático, o rompimento da parede celular das algas ou das cianobactérias pode 
acarretar a liberação de diversas toxinas deletérias à saúde humana e a outros animais.

A dificuldade na remoção das cianotoxinas tem fomentado o estudo de algumas alternativas com o fito de minimizar a afluência de cianobactérias à estação de tratamento. Uma experiência exitosa e implantada a partir de 2002 em uma estação de pequeno porte consistiu na injeção de ar comprimido na captação, por meio de uma estrutura de ferro galvanizado, em forma de anel, dotada de duas fileiras de orifícios posicionadas em ângulos de $45^{\circ}$ e $90^{\circ}$, recebendo ar por meio de um compressor. Embora não atenue a presença das cianotoxinas dissolvidas, este aparato, instalado $30 \mathrm{~cm}$ acima do crivo da bomba, proporcionou aumento significativo da carreira de filtração; decréscimo no tempo de funcionamento da estação de tratamento, com consequente redução do consumo de energia elétrica e de outros custos operacionais; e melhoria da qualidade da água tratada, principalmente no que tange à remoção de sabor e odor (VIANA et al, 2005).

Dos processos comumente inseridos na tecnologia convencional de tratamento de água, são considerados efetivos na remoção de cianotoxinas: a adsorção em carvão ativado e a pós-oxidação, ou seja, a oxidação realizada após a remoção das células viáveis de cianobactérias, ainda que a possibilidade da formação de subprodutos da desinfecção não seja comumente avaliada.

\section{Adsorção com carvão ativado}

O carvão ativado, em pó ou granular, constitui um adsorvente de compostos orgânicos, passíveis de conferir sabor e odor; cor; mutagenicidade e toxicidade, incluindo agroquímicos, geosmina, metilisoborneol (MIB) e cianotoxinas em geral. Entretanto, não se pode generalizar que qualquer tipo de carvão irá adsorver qualquer substância orgânica indesejável, pois a massa molecular desta deve estar diretamente relacionada ao tamanho dos poros dos grãos do carvão (SNOEYINK, 1990).

Segundo a União Internacional de Química Pura e Aplicada (IUPAC), os poros do carvão ativado podem ser classificados em função do diâmetro como macroporos (maiores que $50 \mathrm{~nm}$ ), mesoporos (entre 2 a $50 \mathrm{~nm}$ ) e microporos (menores que $2 \mathrm{~nm}$ ).

Os parâmetros mais importantes para avaliar a capacidade adsortiva de um determinado tipo de carvão são:

- número de iodo: grandeza que expressa a quantidade de iodo adsorvida pelo carvão sob condições específicas. Relaciona-se com a adsorção de pequena massa molecular, e expresso em mg de iodo por grama de carvão ativado;

- índice de azul de metileno: parâmetro que fornece a mesoporosidade do carvão, expresso em mg de azul de metileno por grama de carvão ativado;

- distribuição de tamanho e área superficial dos poros: grandezas representadas pela superfície específica geralmente expressa em $\mathrm{m}^{2} / \mathrm{g}$ (área dos poros por grama de carvão), usualmente determinada pela medida da isoterma de adsorção de moléculas de nitrogênio. Este parâmetro foi proposto por Brunauer, Emmett e Teller, razão pela qual é mencionado em termos de BET- $\mathrm{N}_{2}$. Os três tipos carvões utilizados no tratamento de água têm superfície específica entre 500 e $1.500 \mathrm{~m}^{2} / \mathrm{g}$ ((DI BERNARDO; DANTAS, 2005).

O método BET fornece a área específica (em $\mathrm{m}^{2} / \mathrm{g}$ de adsorvente), que pode ser recoberta por uma camada monomolecular de nitrogênio. A adsorção de nitrogênio à temperatura de $77 \mathrm{~K}$ permite a construção de isotermas de adsorção e dessorção gasosa, das quais se podem extrair informações como a área superficial, volume e distribuição do tamanho dos poros (YENISOY-KARAKAS et al, 2004).

Há alguns modelos matemáticos, que procuram descrever a relação entre quantidade de adsorvato por unidade de adsorvente e a concentração de adsorvato na água, sendo o de Freundlich e o de Langmuir os mais comumente empregados. Na realidade tais modelos constituem regressões lineares, nos quais, por meio do coeficiente de determinação $\left(R^{2}\right)$, verifica-se o quanto a variação total da variável dependente - quantidade de adsorvato (mg ou moles) por massa de adsorvente - é explicada pela reta dos mínimos quadrados.

As principais características do carvão dependem da origem do material empregado (vegetal, animal e mineral) e da ativação (física ou térmica e química). Os vários carvões podem ser diferenciados por suas características físicas e adsortivas. Dentre as primeiras destacam-se ainda - além da quantidade, do volume e da distribuição de tamanhos dos poros - o tamanho dos grãos, a massa específica aparente e dos grãos.

Em relação ao carvão ativado em pó (CAP), faz-se necessário identificar por meio de testes em unidades-piloto ou escala de bancada o tipo e a dosagem apropriada de CAP mais efetivos para adsorção das cianotoxinas presentes na água. Esta dosagem apropriada pode ser significativamente superior às usualmente adotadas para remoção de sabor e odor, e deve ser determinada levando-se em conta a presença de outros compostos orgânicos.

Aliado ao tipo e dosagem de CAP, o ponto de aplicação também adquire relevância no emprego desta técnica. A dispersão do CAP pode suceder na captação, na unidade de mistura rápida e no afluente aos filtros. Na primeira alternativa, obtém-se maior tempo de contato - proporcional ao comprimento da adutora de água bruta - e maior dispêndio do produto pela adsorção de outras substâncias removíveis por coagulação. A alternativa mais empregada da dispersão do CAP na mistura rápida facilita o controle e a perspectiva de automação, mas pode ter a adsorção reduzida pela interferência dos coagulantes. Por fim, a dispersão no afluente aos filtros pode acarretar traspasse dos grãos de CAP na água filtrada.

A capacidade de adsorção de oito tipos de CAP foi avaliada por Donati et al (1994). Os resultados mostraram que os dois carvões 
de madeira foram os mais efetivos na remoção de microcistina-LR, adsorvendo 280 e $220 \mu \mathrm{g} / \mathrm{mg}$. Os carvões menos efetivos foram derivados do coco, adsorvendo 40 e $20 \mu \mathrm{g} / \mathrm{mg}$, e de turfa que também adsorveu $20 \mu \mathrm{g} / \mathrm{mg}$. Para os carvões de madeira, os volumes de mesoporos foram de 0,49 e $0,27 \mathrm{~cm}^{3} / \mathrm{g}$, enquanto para os carvões menos efetivos variaram de 0,02 a $0,19 \mathrm{~cm}^{3} / \mathrm{g}$. Portanto, os autores destacaram que o volume de mesoporos era um indicador da remoção de microcistina-LR, concluindo que a área superficial, o número de iodo e o índice de fenol permitiram apenas uma informação específica e não devem ser usados como únicos indicadores de efetividade do CAP na adsorção de toxinas.

Ainda no mesmo trabalho, comparou-se a eficiência da adsorção de microcistinas dissolvidas em água pura e do rio Murray na Austrália. Observou-se claramente que a eficiência de adsorção dos carvões se reduzia quando era utilizada água do rio. O decréscimo na taxa de adsorção provavelmente deveu-se à competição com os compostos orgânicos naturais pelos sítios de adsorção do CAP.

Kuroda et al (2005) avaliaram a remoção de microcistinas por dez carvões ativados (quatro granulares e seis pulverizados) destinados ao tratamento de água e disponíveis comercialmente por quatro fabricantes do Brasil. Para a realização dos experimentos de adsorção foi preparado um extrato bruto de microcistinas, a partir de cultivos de cepa tóxica de Microcytis ssp. O efeito da adsorção competitiva entre as microcistinas e os compostos orgânicos naturais presentes no extrato reduziu a capacidade adsortiva dos carvões selecionados, registrando-se valores de capacidade máxima de adsorção da ordem de $3 \mu \mathrm{g} / \mathrm{mg}$ para o carvão ativado granular e da ordem de $10 \mu \mathrm{g} / \mathrm{mg}$ para o CAP.

Especificamente com relação às saxitoxinas, Newcombe e Nicholson (2002) relataram que tanto o CAP quanto o granular mostraram-se efetivos na remoção dessas toxinas. Os autores avaliaram cinco CAP distintos, para tempo de contato de uma hora e dosagem de $30 \mathrm{mg} / \mathrm{L}$, e confirmaram que a relação entre o tamanho do composto (massa molecular), o volume e distribuição dos poros no carvão são os principais fatores intervenientes na adsorção.

Ainda focando nas mesmas cianotoxinas, Silva (2005) avaliou a capacidade de adsorção de cinco tipos de CAP produzidos no Brasil. Os carvões selecionados foram de origem animal (osso), vegetal (madeira), coco (casca de coco) e mineral. Os carvões que apresentaram maior capacidade de remoção de saxitoxinas (neoSTX e STX) foram derivados de casca de coco, seguido do carvão derivado de osso. As dosagens de CAP variaram de 3 a $15 \mathrm{mg} / \mathrm{L}$. De modo geral, os carvões avaliados não apresentaram elevada eficiência de remoção. O maior percentual de remoção de saxitoxinas, 33\%, foi obtido com a adição do CAP de coco a uma dosagem de $12 \mathrm{mg} / \mathrm{L}$. Na sequência aparece o CAP de madeira removendo $26 \%$ das saxitoxinas, quando a dosagem adicionada de carvão foi de $15 \mathrm{mg} / \mathrm{L}$, sendo que os outros três carvões não ultrapassaram $21 \%$ de remoção das saxitoxinas originalmente presentes.

\section{Oxidação com compostos de cloro}

Em relação aos oxidantes, é importante destacar, além da dosagem, os efeitos do $\mathrm{pH}$ e do tempo de contato, principalmente quando do emprego de compostos de cloro, e a seleção do ponto de aplicação (pré ou pós-oxidação) sobre a remoção efetiva das cianotoxinas. Especificamente em relação ao $\mathrm{pH}$, as pesquisas desenvolvidas são ainda inconclusivas, provavelmente devido à própria imprecisão para determinação da concentração de cianotoxinas.

Estudo desenvolvido por Nicholson et al (2003) concluiu que a degradação de saxitoxinas não é linear com o aumento do pH e a remoção mais significativa ocorre com pH da ordem de 7,4 para saxitoxinas e da ordem de 8,8 para goniautoxinas. Os autores observaram que mais de $90 \%$ de remoção das cianotoxinas foi obtida com pH de 9,0 e residual de cloro livre de 0,5 mg/L após 30 minutos de tempo de contato.

De acordo com estes autores, foi surpreendente a alta eficiência na degradação de saxitoxinas com valores elevados de pH. Maior eficiência do cloro como agente oxidante ocorre para pH mais baixo devido à prevalência da formação do ácido hipocloroso $(\mathrm{HOCl}) \mathrm{em}$ relação ao íon hipoclorito ( $\left(\mathrm{OCl}^{-}\right)$. Assim, a baixa eficiência na oxidação era esperada para valores de pH mais elevados. Entretanto, as saxitoxinas são moléculas com núcleos de alcaloides purinas que contêm átomos de nitrogênio. Dependendo dos valores de pH, estes átomos de nitrogênio são fortemente protonados. O aumento do pH favorecerá a neutralização dos prótons, tornando as moléculas de saxitoxinas mais suscetíveis à oxidação. Esta característica explica a necessidade de preservação das saxitoxinas em pH ácido.

Nicholson et al (2003) reportaram que microcistinas e nodularias foram rapidamente oxidadas pelo cloro, hipoclorito de cálcio e hipoclorito de sódio, sendo que esse último exigiu dosagem superior à dos dois primeiros. O cloro e o hipoclorito de cálcio removeram 95\% das toxinas com doses de $1 \mathrm{mg} / \mathrm{L}$ (cloro ativo) após um tempo de 30 minutos, ao passo que $5 \mathrm{mg} / \mathrm{L}$ de hipoclorito de sódio foram necessários para cerca de $80 \%$ de remoção no mesmo tempo de contato. Todavia, a remoção de toxinas foi bastante comprometida quando os valores de $\mathrm{pH}$ excediam a 8,0. Para concentrações de cloro ativo de $15 \mathrm{mg} / \mathrm{L}$, a remoção de toxinas reduziu de 95\% para valores inferiores a $80 \%$, quando o valor do $\mathrm{pH}$ superior a 8,0 , sendo que para o hipoclorito a remoção atingiu apenas $40 \%$ com pH igual a 10,0. Bruchet et al (1998) também observaram que as dosagens de cloro requeridas para remoção das cianotoxinas foram superiores aos limites de aceitabilidade para água de consumo.

\section{Objetivo}

Diante do exposto, o objetivo principal do trabalho é avaliar em escala da bancada a eficiência de duas técnicas de tratamento (adsorção e oxidação) na remoção de saxitoxinas produzidas pela espécie 
da cianobactéria C. raciborkii. Em segunda instância, o trabalho visa também a:

- avaliar a aplicabilidade e eficiência de três tipos de CAP usualmente comercializados no Brasil na remoção de saxitoxinas;

- avaliar a aplicabilidade e a eficiência da pós-oxidação utilizando o hipoclorito de cálcio na remoção de saxitoxinas.

\section{Metodologia}

\section{Seleção dos tipos de CAP}

Cinco marcas comerciais de CAP, usualmente empregadas no tratamento de águas de abastecimento, foram preliminarmente selecionadas para execução dos ensaios experimentais em escala de bancada. Os fabricantes forneceram amostras dos carvões juntamente com algumas características, como a granulometria, o número de iodo, umidade, massa específica aparente, índice de fenol, teor de cinzas e superfície da área BET. Entretanto, algumas informações não eram comuns a todos os carvões, o que impossibilitou a comparação entre eles em relação a uma determinada característica. Portanto, visando a comparar as características adsortivas dos carvões, apenas três foram escolhidos para os ensaios de adsorção: Mad-3, osso e mineral.

\section{Caracterização dos carvões}

\section{Análise granulométrica e determinação do número de iodo}

A caracterização granulométrica dos carvões, exceto o mineral, foi realizada pela técnica de difração a laser. A distribuição de tamanhos das peneiras é bastante utilizada, principalmente pelo fato de poder ser obtida facilmente e com grande precisão, em laboratório, para tamanhos maiores que $44 \mu \mathrm{m}$. Abaixo de 44 $\mu \mathrm{m}$, esta medida torna-se mais difícil, e a acuracidade reduz-se proporcionalmente ao tamanho. Abaixo de $20 \mu \mathrm{m}$, medições com micropeneiras são ainda mais imprecisas. Portanto, justifica-se a utilização do difratômetro para determinação da granulometria de carvões ativados em pó.

Devido à natureza irregular das partículas, as distribuições de tamanhos dos difratômetros a laser são definidas como uma distribuição de tamanhos equivalentes de esferas, e esta não é uma medida direta. As distribuições reportadas pelos equipamentos são derivadas a partir de uma medida resultante da integração das partículas com a luz. Os resultados dos carvões analisados foram apresentados por meio de relatório com a distribuição granulométrica das partículas dos carvões. As análises foram realizadas em duplicata.

A análise granulométrica do carvão mineral foi realizada por meio de peneiramento com filete de água, conforme norma brasileira MB3412 (ABNT, 1991B). Vale ressaltar que o carvão mineral apresentou granulometria espessa, o que inviabilizou o uso da difração a laser.
O método utilizado para determinação do número de iodo baseou-se na norma brasileira MB-3410 (ABNT, 1991A).

\section{Determinação da área superficial e da distribuição de tamanho dos poros}

A análise da área superficial BET e da distribuição de tamanho dos poros das amostras de CAP foi realizada em equipamento denominado Autosorb (Quantachrome Corporation), que se baseia na técnica de adsorção de nitrogênio a $77 \mathrm{~K}$.

\section{Fotografias em microscópio eletrônico de varredura}

A microscopia eletrônica de varredura (MEV) é uma ferramenta importante na caracterização da amostra de CAP, proporcionando excelente visualização das características morfológicas das superfícies dos carvões. As análises morfológicas das amostras foram efetuadas por meio de microscópio eletrônico de varredura, marca JOEL, modelo JSM-6360LV, com um sistema de captura de fotos reflex acoplado, utilizando filmes preto e branco de $120 \mathrm{~mm}$.

\section{Cultivo de cianobactérias e extração de saxitoxinas}

As cianobactérias foram cultivadas em meio líquido WC, a partir de quatro cepas da espécie C. raciborskii coletadas em uma lagoa em meio urbano, as quais apresentam ótimo crescimento e mantidas rotineiramente no laboratório. Os frascos contendo a cultura foram mantidos em ambiente climatizado, com controle da temperatura (a $24^{\circ} \mathrm{C}$ ) e da intensidade luminosa, em torno de $80 \mu \mathrm{mol} . \mathrm{cm}^{2} \mathrm{~s}^{-1}$, e com um fotoperíodo de 12 horas claro/12 horas escuro. O cultivo na fase de crescimento exponencial continha uma concentração de C. raciborskii da ordem de $10^{6} \mathrm{cel} / \mathrm{mL}$. Neste momento as células necessitavam de mais nutrientes para continuar crescendo. Portanto, parcela das células que atingiam o crescimento exponencial era adicionada em sete Erlenmeyer de 2 L com meio de cultura WC (pH de 7,22) totalizando $10 \mathrm{~L}$ de cultivo.

A metodologia implementada no Laboratório de Botânica da Universidade Federal de Minas Gerais (UFMG) para liberar a toxina intracelular a ser usada nos experimentos preconizava o cultivo na fase exponencial de crescimento das cianobactérias, submetido à filtração a vácuo em membranas de borosilicato com abertura de poro de 0,45 $\mu \mathrm{m}$ e posteriormente liofilizado. Para extração da toxina intracelular, o filtro contendo o material seco retido era fragmentado em um béquer. Uma solução de ácido acético 0,05 M era então vertida no béquer até cobrir todos os pedaços do filtro. O béquer era vedado com filme de PVC e submetido à agitação vigorosa por cerca de uma hora. Após este procedimento, o material era centrifugado a $3.500 \mathrm{rpm}$ por 15 minutos. O precipitado era novamente extraído com solução de ácido acético e centrifugado sob as mesmas condições anteriores (esse processo era realizado por três vezes consecutivas). Os sobrenadantes eram misturados e o pH 
ajustado para valores entre 3,0 e 4,0 antes do congelamento, pois isto aumentaria a sua estabilidade por vários meses (até um ano).

\section{Análise de saxitoxinas}

Inicialmente, tencionava-se efetuar as análises de saxitoxinas utilizando-se cromatografia líquida de alta eficiência (CLAE) com derivatização pós-coluna e detecção de fluorescência. Todavia, os cromatogramas obtidos pelo equipamento disponibilizado pela companhia estadual de saneamento apresentaram picos sobrepostos e tempos de retenção com atraso em relação aos padrões, indicativos de metodologia ainda não totalmente implantada. Desta forma, as análises de saxitoxinas foram realizadas por meio do teste imunoensaio competitivo utilizando kit ELISA (Ridascreen@Fast Saxitoxin), de acordo com as instruções expressas no manual

O teste ELISA (Enzyme-Linked ImmunoSorbent Assay) consiste em uma técnica de detecção imunológica de fácil operação, rápido resultado e de grande sensibilidade, sendo em algumas circunstâncias mais sensível do que o método cromatográfico para
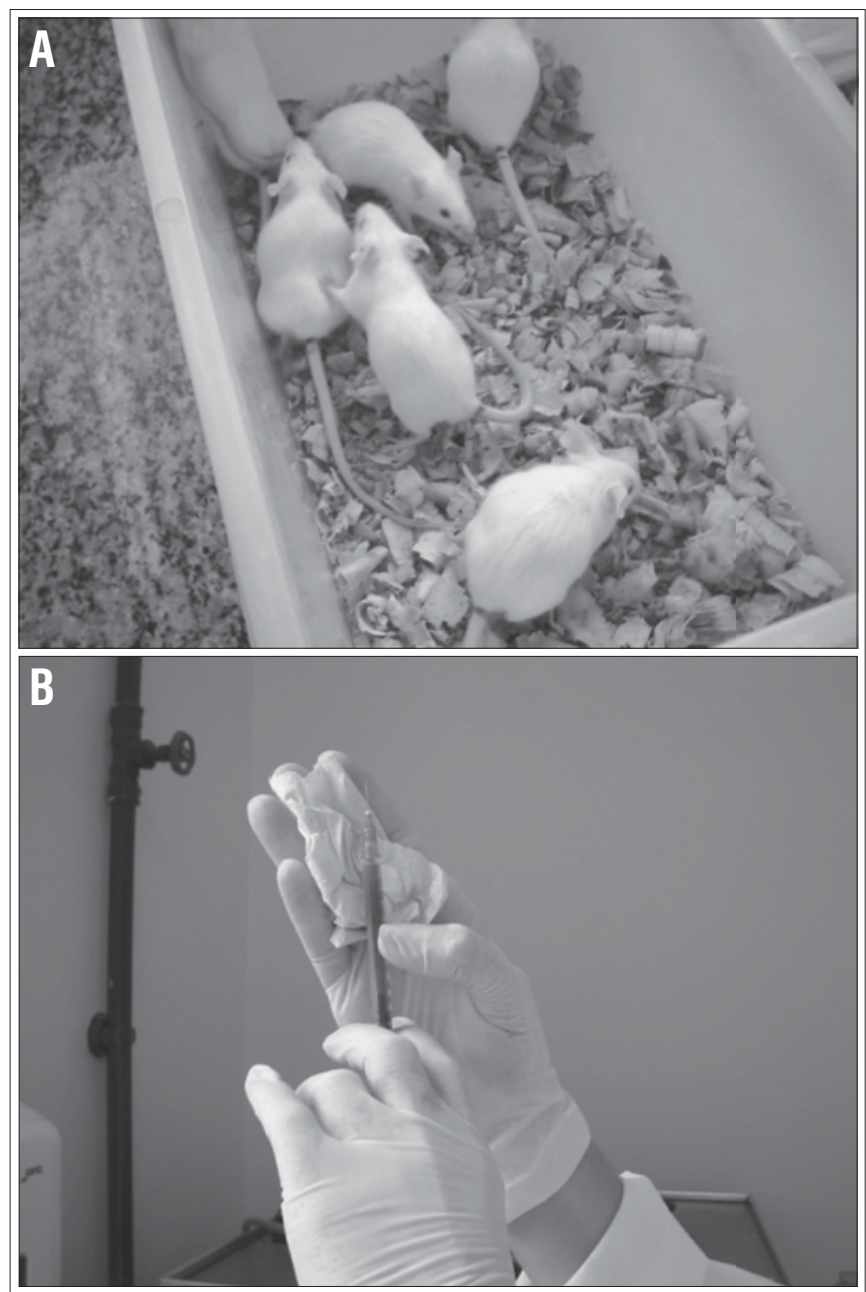

Figura 1 - Fotos mostrando camundongos Swiss ssp. utilizados nos teste toxicológico (A) e as dosagens injetadas (B) determinar traços de microcistinas na água. Entretanto, algumas variantes de microcistinas não apresentam reatividade com os anticorpos usados no teste, não sendo, portanto, detectadas (CARMICHAEL, 1994). Assim, recomenda-se para programas de monitoramento de cianotoxinas na água, principalmente de microcistinas, que o teste imunoensaio competitivo seja suplementado com análise qualitativa por métodos cromatográficos (HENRIKSEN; MOESTRUP, 1997).

Esta técnica já teve sua validade comprovada no que concerne à determinação de saxitoxinas presentes em peixes e mariscos. No presente trabalho optou-se por interpretar os resultados em termos de saxitoxinas equivalentes para cada técnica de tratamento, pois o teste ELISA não distingue as toxinas presentes. Não houve necessidade de concentração das toxinas, uma vez que o limite de detecção do kit Elisa é de 2,5 $\mu \mathrm{g} / \mathrm{L}$. Ao contrário, na maioria dos casos, as amostras tiveram que ser diluídas devido à maior concentração no extrato.

Para quantificar as saxitoxinas presentes no extrato, proveniente da lise das células de C. raciborskii, foi necessário encaminhar a amostra para o Laboratório de Ecofisiologia e Toxicologia de Cianobactérias (LETC) da Universidade Federal do Rio de Janeiro (UFRJ), no qual se dispõe da metodologia padronizada para quantificação de saxitoxinas. Tal análise tinha o objetivo de quantificar a produção de saxitoxinas extraídas da lise celular desta cepa de C. raciborskii. Posteriormente, verificou-se a fidedignidade do teste de imunoensaio pela comparação das concentrações dos padrões externos de neoSTX e STX. Nesta avaliação observou-se que as concentrações de saxitoxinas (neoSTX e STX) determinadas pelo kit Elisa se apresentaram bastantes coerentes em relação às concentrações dos padrões.

\section{Testes de toxicidade}

Nos ensaios toxicológicos foram utilizados camundongos da espécie Swiss ssp, injetando-se doses de extratos de cianobactérias (liofilizados) proveniente do cultivo de C. raciborskii. Nestes ensaios foram preparadas concentrações crescentes de extrato nas doses: 41, 199 e 377 mg/kg (mg de material algáceo seco/kg por peso corpóreo dos camundongos). Para cada dose foram utilizados dois camundongos, um macho e uma fêmea, pesando entre 22 a 27 g, tendo sido injetado um volume de $1 \mathrm{~mL}$ por meio de injeções intraperitoneais. Após as injeções, os animais foram mantidos em local arejado com alimento e água, sob observação durante 24 horas (Figura 1).

\section{Preparo da água de estudo}

A metodologia empregada para a produção de água sintética consistia na diluição do extrato de saxitoxinas proveniente da lise celular em $500 \mathrm{~mL}$ de água destilada (3 mL de extrato para 497 $\mathrm{mL}$ de água destilada). Como o extrato apresentava-se acidificado (pH de 3,0 a 4,0), ajustava-se o pH para 7,0. Para cada análise 
realizada no kit Elisa fazia-se necessário elaborar uma curva padrão, composta por seis pontos, totalizando doze pontos, pois a leitura era realizada em duplicata. Como medida de economia decorrente do alto custo do kit, optou-se em realizar as análises em bateladas, além do que os resultados eram balizados pela mesma curva. Como consequência, as concentrações iniciais de saxitoxinas (Co) nos experimentos apresentaram maior variabilidade da ordem de 15 a $75 \mu \mathrm{g} / \mathrm{L}$.

\section{Ensaios de adsorção de saxitoxinas}

Os ensaios de adsorção foram realizados em uma sala mantida sob temperatura aproximadamente constante, utilizando-se equipamento de jar test (Nova Ética) adaptado, com seis jarros de $1.000 \mathrm{~mL}$, apto à coleta simultânea de água decantada e capacidade de imprimir gradientes de velocidade de 10 a $2.000 \mathrm{~s}^{-1}$ (Figura 2). O tempo de contato utilizado nos ensaios foi de duas horas, correspondendo aproximadamente ao período de permanência da água em uma estação de tratamento convencional. Vale mencionar que a norma D3860-98 da American Society for Testing and Materials - ASTM (2000) estabelece o mesmo tempo como suficiente para adsorção de moléculas.

A massa de carvão ativado e o volume da amostra utilizados nos ensaios de adsorção foram definidos com base nas recomendações da norma D3860-98, arroladas na Tabela 1.

Foi adotado volume para a amostra de $500 \mathrm{~mL}$ e dosagens de CAP de 5, 15, 20 e $50 \mathrm{mg} / \mathrm{L}$, correspondendo a massas de 2,5, 7,5, 10 e $25 \mathrm{mg}$, respectivamente. Tais dosagens basearam-se nas faixas usualmente utilizadas em estações de tratamento de água. Valores superiores a $50 \mathrm{mg} / \mathrm{L}$ de CAP tornam-se inviáveis economicamente para as concessionárias, além de outros possíveis problemas relacionados à grande produção de lodo nos decantadores e à perspectiva de precoce colmatação dos filtros.

De acordo com as premissas da D3860-98 (ASTM, 2000), as amostras eram agitadas para manter o CAP em suspensão a um gradiente de velocidade da ordem de $220 \mathrm{~s}^{-1}$. É importante salientar que tal procedimento para adsorção de saxitoxinas distingue-se dos padrões convencionais de tratamento de água. A despeito do gradiente de velocidade de mistura rápida ser comumente superior a $600 \mathrm{~s}^{-1}$, o grau de agitação nas etapas subsequentes da potabilização é significativamente inferior ao recomendado pela norma americana.

Após o tempo de contato de duas horas, as amostras eram imediatamente filtradas em membranas com abertura dos poros de 0,45 $\mu \mathrm{m}$ para separação do CAP. Para evitar interferências relativas às diferenças no tempo de contato em relação à etapa de filtração, o início do ensaio foi realizado com defasagem de $10 \mathrm{mim}$ de um frasco para outro. Por fim, submetia-se a fração filtrada à leitura do pH e análises da concentração de saxitoxinas. Esses experimentos foram realizados em duplicata para cada dosagem de CAP.

\section{Ensaios de oxidação de saxitoxinas}

Em procedimento semelhante, os ensaios de cloração foram realizados em quadruplicata utilizando o mesmo equipamento e recipientes de 1.000 mL. Com o objetivo de verificar a eficiência da cloração para menores concentrações de saxitoxinas, a metodologia empregada no preparo da água sintética para estes ensaios consistia na adição de $2 \mathrm{~mL}$ de extrato de saxitoxinas para $498 \mathrm{~mL}$ de água destilada. $\mathrm{O}$ pH era ajustado para valores entre 6,0 a 7,0.

Os tempos de contato utilizados foram de 30 e 60 minutos e as dosagens de 0,9, 1,2 e 1,5 mg/L de cloro ativo. Os tempos de contato foram definidos em relação às recomendações da Portaria 518 (30 minutos) e à perspectiva da desinfecção se consubstanciar na primeira unidade de reservação a jusante da estação de tratamento, conforme ocorre em diversos sistemas do País. As dosagens referem-se ao intervalo usualmente utilizado para desinfecção de águas filtradas. As amostras foram agitadas, simulando a homogeneidade conferida pelas chicanas do tanque de contato. Após o tempo de contato, a amostra coletada era submetida à leitura de pH e análises de saxitoxinas.

\section{Análise estatística dos resultados}

Inicialmente, para todas as dosagens de CAP e hipoclorito de cálcio foram calculadas as estatísticas descritivas relativas ao número de dados, média, mediana, mínimo, máximo, amplitude (máximomínimo), desvio padrão e coeficiente de variação.

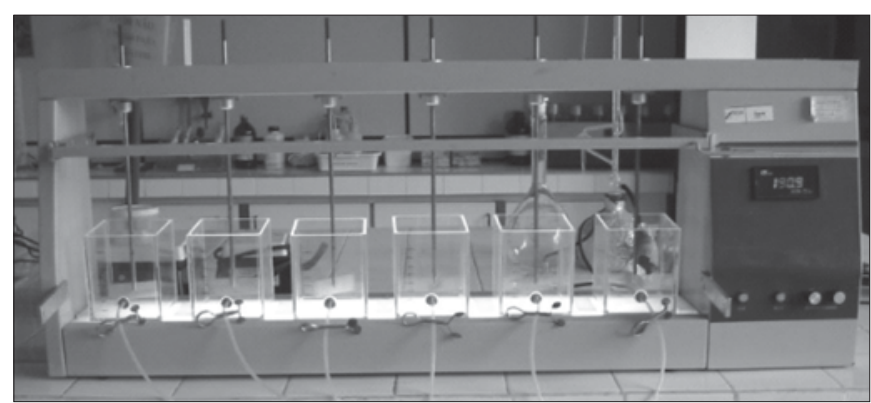

Figura 2 - Equipamento de jar test adaptado com jarros de $1.000 \mathrm{~mL}$ utilizados nos ensaios

Tabela 1 - Volumes de amostras e massas de carvão para intervalos de concentração de adsorvato

$\begin{array}{lcc}\begin{array}{l}\text { Concentração de } \\ \text { adsorvato } \\ (\mathrm{mg} / \mathrm{L})\end{array} & \begin{array}{c}\text { Volume da amostra } \\ (\mathrm{mL})\end{array} & \begin{array}{c}\text { Massa de carvão } \\ \text { sugerida }(\mathrm{mg})\end{array} \\ \leq 10 & 500 & 1,0 ; 2,5 ; 5,0 ; 7,5 ; 10,0 ; \\ & & 25,0 \text { e } 50,0\end{array}$

Fonte: American Society for Testing Materials, 2000. 
Para a realização dos testes de hipóteses, classificados em paramétricos e não-paramétricos, avaliaram-se a dosagem e o tipo de CAP, a dosagem de cloro e o tempo de contato na remoção de saxitosinas.

Os testes paramétricos constituem-se de testes estatísticos que se caracterizam pela premissa da distribuição normal da população (aqui, os resultados dos ensaios) ou cujo modelo de distribuição dos dados seja previamente conhecido. Em contrapartida, os testes não-paramétricos não carecem do conhecimento prévio do modelo distributivo da população da qual os dados foram extraídos (NAGHETTINI; PINTO, 2007).
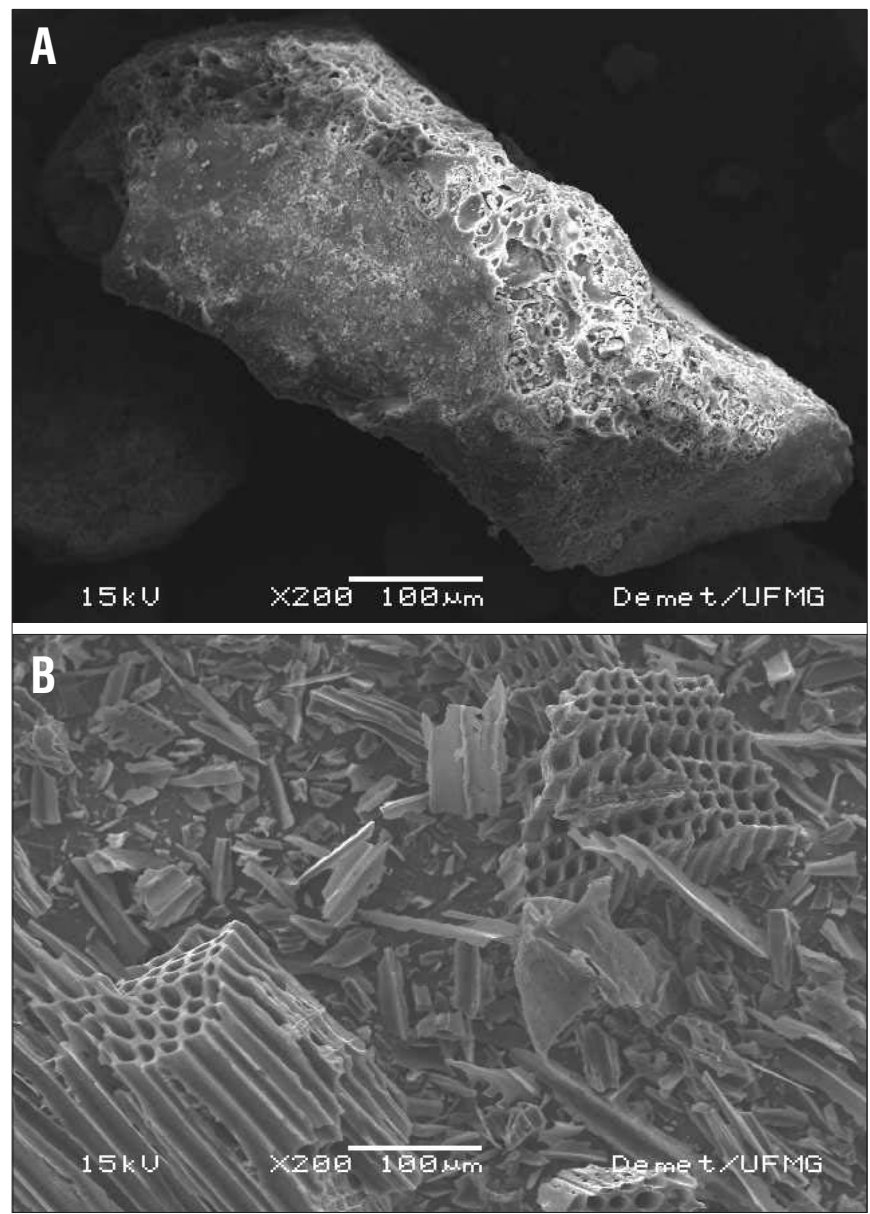

Figura 3 - Fotografias de microvarredura mostrando CAP mineral $(A)$ e CAP MAD-1 (B) com aumento de 200 vezes
No presente trabalho não foi possível admitir que os resultados obtidos possuíssem distribuição normal, pelo pequeno tamanho da amostra. Portanto, com o objetivo de avaliar a análise de variância dos tipos de carvões utilizados, aplicaram-se testes não-paramétricos.

Utilizou-se o teste não-paramétrico Kruskal-Wallis, cujo objetivo consiste em estimar as variações sistemáticas entre medianas e determinar se as mesmas são significativas, ou seja, verificar a existência ou não da hipótese nula. O teste de Kruskal-Wallis foi utilizado para verificar as análises de variância entre as dosagens de CAP estabelecidas e entre os tipos de carvões, ou seja, análises entre grupos e intragrupos. Em outra análise, avaliou-se a variância entre as dosagens de hipoclorito de cálcio e entre os tempos contato. Todos os cálculos, provenientes do teste de Kruskal-Wallis, realizaram-se com o auxílio do software Statistica 6.1. Vale ressaltar que foram utilizados todos os dados referentes às réplicas experimentais, uma vez que com maior número de dados se obtém uma melhor confiabilidade estatística.

\section{Resultados e discussão}

\section{Caracterização dos carvões}

A caracterização dos carvões disponíveis para o estudo está apresentada na Tabela 2.

Pelos resultados de caracterização dos carvões, observa-se que a sequência dos valores da superfície específica em ordem decrescente é a mesma para o número de iodo e o volume de microporos para os carvões de madeira (MAD-1, MAD-2 e MAD-3), osso e mineral. Verifica-se, portanto, uma correspondência direta entre ambos os parâmetros, isto é, elevada superfície específica associa-se a altos valores de número de iodo e maiores volumes de microporos. Os carvões de madeira apresentaram o maior volume de microporos, comparado aos demais. Nas fotografias em MEV evidenciaram-se as diferenças morfológicas de cada CAP, e ainda o arranjo e a conformação dos poros. Foi observado que os carvões vegetais apresentaram uma superfície bastante porosa comparada aos carvões de osso e mineral, que por sua vez, apresentaram uma superfície bastante irregular, não ficando clara a visualização dos poros, conforme mostra a Figura 3.

Tabela 2 - Resumo das características dos carvões disponibilizados para a pesquisa

\begin{tabular}{|c|c|c|c|c|c|c|c|}
\hline \multirow[t]{2}{*}{ CAP } & \multirow{2}{*}{$\begin{array}{l}\text { Número de iodo } \\
\left(\mathrm{mgL}_{2} / \mathrm{g}\right)^{\star}\end{array}$} & \multirow[t]{2}{*}{ Densidade } & \multirow[t]{2}{*}{ Área BET $\left(\mathrm{m}^{2} / \mathrm{g}\right)$} & \multirow{2}{*}{$\begin{array}{l}\text { Volume de } \\
\text { poros }\left(\mathrm{cm}^{3} / \mathrm{g}\right)\end{array}$} & \multicolumn{3}{|c|}{ Distribuição dos tamanhos dos poros $\mathrm{cm}^{3} / \mathrm{g}(\%)$} \\
\hline & & & & & Microporos & Mesoporos & Macroporos \\
\hline MAD-1 & $920,71 \pm 10,62$ & 2,05 & 945 & 0,634 & $0,330(62)$ & $0,038(6)$ & $0,201(32)$ \\
\hline MAD-2 & $824,12 \pm 2,73$ & 2,28 & 823 & 0,649 & $0,380(58)$ & $0,074(11)$ & $0,215(31)$ \\
\hline MAD-3 & $754,13 \pm 5,31$ & 1,70 & 774 & 0,498 & $0,300(61)$ & $0,036(7)$ & $0,120(32)$ \\
\hline Osso & $137,74 \pm 0,25$ & 2,65 & 122 & 0,320 & $0,128(40)$ & $0,160(50)$ & $0,032(10)$ \\
\hline Mineral & $105,03 \pm 1,54$ & 2,77 & 2,5 & 0,005 & $0,003(55)$ & $0,001(25)$ & $0,001(25)$ \\
\hline
\end{tabular}

*Média \pm desvio padrão. 
Conforme mencionado, após a caracterização dos carvões, com o objetivo de reduzir o número de análises devido ao elevado custo do kit ELISA, decidiu-se efetuar a comparação abarcando três tipos de CAP - madeira (MAD-3), osso e mineral.

\section{Análise de toxicidade}

Os resultados dos bioensaios evidenciaram a elevada toxicidade da cepa. Os animais manifestaram efeitos de letalidade em um período máximo de cinco minutos, apresentando sintomas neurotóxicos (sintomas de contração muscular, taquicardia, respiração ofegante e parada respiratória).

Injetaram-se em seis camundongos duas doses semelhantes para cada par de camundongos, totalizando três doses médias letais (mg de peso seco de células de C. raciborskii por kg de peso corpóreo). As duas primeiras doses médias letais correspondentes a 377,22 e 198,59 mg/kg foram responsáveis pela morte de todos os camundongos. A última dose de $41 \mathrm{mg} / \mathrm{kg}$ de peso corpóreo acarretou a morte de apenas um camundongo. Contudo, o número de camundongos (dois) inviabiliza uma definição mais peremptória desta dose como a $\mathrm{DL}_{50}$. Por fim, de acordo com a classificação sugerida por Lawton et al (1994), valores menores que $100 \mathrm{mg}$ de peso seco de células de cianobactérias por kg de peso corpóreo, pode-se considerar a cepa com toxicidade alta. Como a dosagem de $41 \mathrm{mg} / \mathrm{kg}$ foi responsável pela morte de um camundongo, considerou-se a cepa como extremamente tóxica.

\section{Avaliação da capacidade adsortiva dos carvões}

Nesta etapa da pesquisa os valores apresentados para concentrações iniciais e finais referem-se a saxitoxinas equivalentes, uma vez que os testes ELISA não são capazes de distinguir cada toxina. A conjunção dos resultados dos ensaios de adsorção está apresentada na Figura 4.

Pela análise dos resultados expressos na Figura 4, verifica-se que o CAP de madeira apresentou remoção média de 58\% e o CAP de osso de $45 \%$ e, que, principalmente para o primeiro, a porcentagem de remoção se elevou com o aumento da dosagem. Embora especulativa, a possibilidade de algum erro na análise de saxitoxinas para a dosagem de 20 mg/L de CAP de osso emerge pela comparação com os demais resultados. Em relação ao CAP mineral, observa-se uma tendência de remoção de aproximadamente constante da ordem de $40 \%$, indicando que o tempo de duas horas foi suficiente para saturar o CAP. Tal fato pode ser explicado pela baixa quantidade de poros presentes na superfície do carvão.

Em relação às características dos carvões, verificou-se melhor remoção de saxitoxinas para o CAP que obteve maior número de iodo, consequentemente maior volume de microporos (Tabela 3). Esta assertiva contrapõe-se ao trabalho de Silva (2005), no qual os carvões capazes de maior remoção de saxitoxinas caracterizavam-se por apresentar o maior volume de mesoporos.

De forma geral, não foi obtido êxito nos ajustes aos modelos de adsorção de Frendlich e Languimir, dificultando a análise da influência das características de cada carvão na capacidade de remoção de

Tabela 3 - Resultados do teste de Kruskal-Wallis para as distintas dosagens de CAP

\begin{tabular}{lll}
$\begin{array}{l}\text { Tipo de CAP } \\
\text { Mineral }\end{array}$ & Rejeita $\mathrm{H}_{0}$ & Aceita $\mathrm{H}_{0}$ \\
\hline Osso & - & Todas as dosagens \\
& Entre 5 e $20 \mathrm{mg} / \mathrm{L}$ & $\begin{array}{l}\text { Entre } 5 \text { e } 15,5 \text { e } 50,15 \text { e } 20, \\
20 \text { e } 50,15 \text { e } 50 \mathrm{mg} / \mathrm{L}\end{array}$ \\
Madeira & Entre 15 e $50 \mathrm{mg} / \mathrm{L}$ & $\begin{array}{l}\text { Entre } 5 \text { e } 15,5 \text { e } 50,15 \text { e } 20, \\
20 \text { e } 50,5 \text { e } 20 \mathrm{mg} / \mathrm{L}\end{array}$ \\
\hline
\end{tabular}

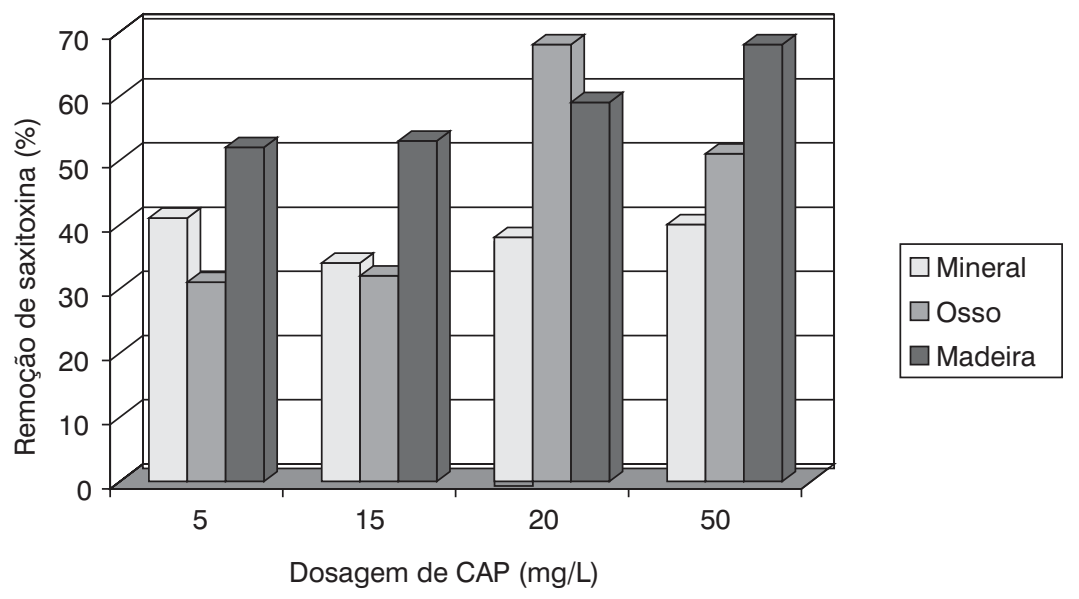

Figura 4 - Comparação da eficiência dos três tipos de CAP na adsorção de saxitoxinas 
saxitoxinas. Esta dificuldade também se manifestou no trabalho de Silva (2005). Acredita-se na hipótese de melhores ajustes na utilização da toxina purificada, uma vez que ao se utilizar extrato bruto, a matéria orgânica e os restos celulares competirão pelos mesmos sítios de adsorção do carvão ativado.

Em relação ao trabalho de Newcombe e Nicholson (2002), a remoção de saxitoxinas atingiu 100\% para uma dosagem de $30 \mathrm{mg} / \mathrm{L}$ utilizando-se cinco carvões diferentes e um tempo de detenção de uma hora, contrapondo-se com os resultados obtidos no presente trabalho. Entretanto, é importante destacar que naquele trabalho não se indica o valor da concentração inicial de saxitoxinas e caso este valor for relativamente baixo, a concentração efetivamente removida é pequena.

\section{Avaliação da oxidação com cloro na remoção de saxitoxinas}

Para os ensaios de oxidação foi possível variar as dosagens de hipoclorito de cálcio e o tempo de detenção (30 e 60 minutos), com a concentração de saxitoxinas $(15,80 \pm 0,20 \mu \mathrm{g} / \mathrm{L})$ e pH $(6,3 \pm 0,2)$ aproximadamente constantes. Os resultados estão apresentados na Figura 5.

Da análise dos resultados da Figura 5 depreendem-se diferenças pouco significativas entre os tempos de contato. É importante também observar o elevado percentual de remoção, superando 80\%, praticamente obedecendo ao valor máximo permissível recomendado pela Portaria $518(3 \mu \mathrm{g} / \mathrm{L})$.

Nicholson et al (2003) relataram que o cloro e o hipoclorito de cálcio removeram 95\% das microcistinas e nodularias para dosagens de $1 \mathrm{mg} / \mathrm{L}$ (cloro ativo) após um tempo de 30 minutos, assemelhando- se aos resultados obtidos para a oxidação de saxitoxinas no presente trabalho. Porém, de acordo com os mesmos pesquisadores, a eficiência da cloração depende do_valor do pH e da toxina em questão, sendo eficiente a degradação de saxitoxinas a elevados valores de $\mathrm{pH}$. $\mathrm{Na}$ presente pesquisa, a opção por ensaios com pH mais baixo, aliado ao alto custo dos kits ELISA, fiou-se também na recomendação da Portaria 518 de realizar a desinfecção preferencialmente com pH inferior a 8,0 .

\section{Análise de variância}

\section{Adsorção}

Em primeira instância, avaliou-se a hipótese nula $\mathrm{H}_{0}$ de que não há diferença entre as medianas referentes a cada dosagem de CAP. A partir da síntese apresentada na Tabela 3, observa-se que as variações de dosagens do CAP mineral apresentaram resultados estatisticamente semelhantes na remoção de saxitoxinas. Esta assertiva confirma-se na uniformidade da eficiência do CAP mineral, da ordem de 40\%, para as quatro dosagens avaliadas (Figura 4).

Para os carvões originários de osso e madeira há diferença estatística apenas entre as dosagens de 5 e $20 \mathrm{mg} / \mathrm{L}$ e 15 e $50 \mathrm{mg} / \mathrm{L}$, respectivamente.

A segunda avaliação centrou-se no tipo de CAP, conforme mostra os resultados da Tabela 4.

De acordo com os resultados listados na Tabela 4, apenas para a dosagem de $15 \mathrm{mg} / \mathrm{L}$ não há diferença significativa entre os três carvões avaliados, premissa corroborada pelos resultados apresentados na Figura 4. Portanto, pode-se afirmar que a maior eficiência na adsorção de saxitoxinas relaciona-se ao tipo de carvão e à dosagem adequada.

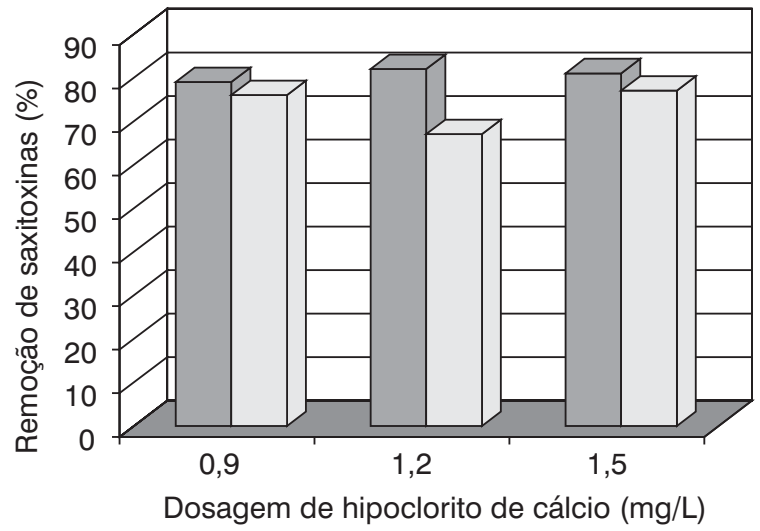

$$
\begin{aligned}
& \square \text { Tempo de contato }=30 \\
& \text { minutos } \\
& \square T e m p o \text { de contato }=60 \\
& \text { minutos }
\end{aligned}
$$

Figura 5 - Resultados dos ensaios de oxidação de saxitoxinas 


\section{Oxidação}

Seguindo o mesmo raciocínio, as análises de variância por meio do teste de Kruskal-Wallis direcionaram-se para o tempo de contato e as dosagens de hipoclorito de cálcio. Em relação à primeira variável, o teste indicou que não há diferença estatisticamente significativa entre as dosagens para os dois tempos de contato. Vale afirmar, que o aumento do tempo de contato não acarretou elevação na oxidação de saxitoxinas. Tal constatação é corroborada pelos resultados apresentados na Figura 5, na qual se evidencia eficiência de oxidação praticamente equânime para as dosagens de 0,9 e 1,5 $\mathrm{mg} / \mathrm{L}$, e da mesma ordem de grandeza para todos ensaios realizados. A segunda análise apresentou o mesmo resultado, indicando que não há diferença estatística entre as dosagens aplicadas na oxidação de saxitoxinas.

\section{Considerações finais}

A análise de saxitoxinas por meio do ensaio imunocompetitivo apresentou resultados bastante coerentes em relação às concentrações dos padrões externos de neoSTX e STX, podendo se tornar - a despeito do custo dos kits ELISA - em alternativa viável às concessionárias dos sistemas de abastecimento de água.

Dentre os carvões avaliados, pode-se concluir que a eficiência está diretamente relacionada ao tipo de carvão e à dosagem aplicada. Os resultados indicaram supremacia do CAP de madeira sobre os demais e maior eficiência na remoção de saxitoxinas (68\%) foi obtida para dosagem $50 \mathrm{mg} / \mathrm{L}$

Dentre os parâmetros de caracterização do CAP, ou seja, número de iodo, distribuição granulométrica, área superficial BET, volume total de poros e volume de micro, meso e macroporos, o volume total de poros na superfície parece melhor representar a capacidade de adsorção de saxitoxinas. Ainda que um estudo especificamente centrado no volume total de poros não tenha sido realizado, o mencionado melhor desempenho do CAP de madeira, cujo volume total de poros supera ao dos demais carvões avaliados, fortalece esta assertiva. Ainda em relação à caracterização dos carvões, conclui-se que a mesma é de extrema importância, visto_que as informações fornecidas pelos fabricantes a respeito dos carvões utilizados nos ensaios diferiram significativamente às características posteriormente determinadas na pesquisa.

A técnica de adsorção para remoção de saxitoxinas por meio do CAP não foi eficiente o bastante para atingir o valor máximo permissível recomendado pela Portaria $518(3 \mu \mathrm{g} / \mathrm{L})$. Todavia, as
Tabela 4 - Resultados do teste de Kruskal-Wallis para os três tipos de CAP

\begin{tabular}{lll} 
Dosagem $(\mathrm{mg} / \mathrm{L})$ & Rejeita $\mathrm{H}_{0}$ & Aceita $\mathrm{H}_{0}$ \\
\hline 5 & CAP osso e madeira & $\begin{array}{l}\text { CAP osso e mineral, CAP } \\
\text { madeira e mineral }\end{array}$ \\
15 & - & Todos os carvões \\
\hline 20 & CAP mineral e osso & $\begin{array}{l}\text { CAP madeira e osso, CAP } \\
\text { madeira e mineral }\end{array}$ \\
50 & CAP mineral e madeira & $\begin{array}{l}\text { CAP madeira e osso, CAP } \\
\text { osso e mineral }\end{array}$ \\
\hline
\end{tabular}

concentrações removidas foram altas (adsorvendo com CAP de madeira mais de $16 \mu \mathrm{g} / \mathrm{L}$ de saxitoxinas de uma concentração inicial de 24,8 $\mu \mathrm{g} / \mathrm{L})$, mesmo com baixas dosagens.

Embora a possível formação de subprodutos não tenha sido avaliada, a oxidação por meio de hipoclorito de cálcio apresentou bom desempenho na remoção de saxitoxinas, inclusive quanto ao enquadramento ao valor máximo permissível determinado pela Portaria 518. Neste contexto, os tempos de contato de 30 e 60 minutos não se apresentaram relevantes na remoção de saxitoxinas.

A partir da metodologia empregada e dos resultados dos ensaios experimentais, recomenda-se:

- avaliação da capacidade adsortiva do CAP para águas naturais, verificando o efeito da competição exercida pela matéria orgânica presente;

- avaliação da influência do coagulante e do oxidante sobre a capacidade adsortiva do CAP;

- verificação da real influência do pH na cloração de saxitoxinas;

- estudar formação de subprodutos gerados na oxidação de saxitoxinas e eventual potencialidade tóxica dos mesmos.

\section{Agradecimentos}

Os autores agradecem aos revisores do artigo, à Financiadora de Estudos e Projetos (Finep) pelo suporte financeiro necessário à montagem do aparato experimental e realização dos ensaios, no contexto do Programa de Pesquisa em Saneamento Básico (Prosab), Edital 4, ao Conselho Nacional de Desenvolvimento Científico e Tecnológico (CNPq), à Coordenação de Aperfeiçoamento de Pessoal de Nível Superior (Capes), pela concessão das bolsas de estudo vinculadas à pesquisa, e à Fundação de Amparo à Pesquisa do Estado de Minas Gerais (Fapemig), pelo apoio no bojo do Programa Pesquisador Mineiro (processo 26017). 


\section{Referências}

ASSOCIAÇÃO BRASILEIRA DE NORMAS TÉCNICAS (ABNT). ABNT MB3410. Carvão ativado pulverizado: determinação do número de iodo. Rio de Janeiro, 1991A 1991B.

ABNT MB-3412. Determinação granulométrica. Rio de Janeiro,

\section{AMERICAN SOCIETY FOR TESTING MATERIALS. Standards on activated} carbon. 2. ed. Philadelphia, 2000.

BRASIL. Ministério da Saúde. Normas e padrão de potabilidade da água destinada ao consumo humano. Portaria 518. Brasília, 2004.

BRUCHET, A. et al. Algal toxins in surface waters: analysis and treatment. Water Supply, v. 16, n. 1/2, p. 619-623, 1998.

CARMICHAEL, W.W. The toxins of cyanobacteria. Scientific American, v. 270, n. 1, p. 78-86, 1994

Cyanobacteria secondary metabolites: the cyanotoxins. Journal of Applied Bacteriology, v. 72, n. 6, p. 445-459, 1992.

CHORUS, I.; BARTRAM, J. (Ed.) Toxic cyanobacteria in water: a guide to their public health consequences, monitoring and management. London: E\&FN Spon, 1999.

DI BERNARDO, L.; DANTAS, A.D. Métodos e técnicas de tratamento de água. 2. ed. Rio de Janeiro: Abes, 2005.

DONATI, C. et al. Microcystin-LR adsorption by powdered activated carbon. Water Research, v. 8, n. 28, p. 1735-1742, 1994.

HENRIKSEN, P.; MOESTRUP, O. Seasonal variation in microcystin contents of Danish cyanobacteria. Nature Toxins, v. 5, n. 3, p. 99-106, 1997.

KURODA, E.K. et al. Caracterização e escolha do tipo de carvão ativado a ser empregado no tratamento de água contendo microcistinas. In: CONGRESSO BRASILEIRO DE ENGENHARIA SANITÁRIA E
AMBIENTAL, Anais Eletrônicos do Congresso Brasileiro de Engenharia Sanitária e Ambiental, Campo Grande, 2005.

LAWTON, L.A. et al. Evaluation of assay methods for the determination of cyanobacterial hepatotoxicity. In: CODD, G.A. et al (Ed.) Detection methods for cyanobacterial toxins. United Kingdom: The Royal Society of Chemistry, 1994. p. 111-116.

NAGHETTINI, M.; PINTO, E.J.A. Testes de hipóteses. In: NAGHETTINI, M.; PINTO, E.J.A. Hidrologia estatística, Belo Horizonte: CPRM, 2007. p. $243-288$

NEWCOMBE, G.; NICHOLSON, B. Treatment options for the saxitoxin class of cyanotoxins. Water Science and Technology: Water Supply, v. 2, n. 5-6, p. 271-275, 2002.

NICHOLSON, B.C. et al. Chlorination for degrading saxitoxins (paralytic shellfish poisons) in water. Environmental Technology, v. 24, n. 11, p. 1341-1348, 2003.

SILVA, A.S. Avaliação da capacidade de remoção de saxitoxinas por diferentes tipos de carvão ativado em pó (CAP) produzidos no Brasil. Dissertação (Mestrado) - UnB, 2005.

SIVONEN, K.; JONES, G. Cyanobacterial toxins. In: CHORUS, I.; BARTRAM, J. (Ed.) Toxic cyanobacteria in water. London: E\&FN Spon, 1999. p. 41-111.

SNOEYINK, V. Adsorption of organic compounds. In: PONTIUS, F.W. Water quality and treatment. 4. ed. New York: AWWA, 1990. p. 781-867.

YENISOY-KARAKAS, S. et al. Physical and chemical characteristics of polymer-based spherical activated carbon and its ability to adsorb organics. Carbon, Elsevier Science Publisher, Oxford, v. 42, n.3, p. 477-484, 2004.

VIANA, M. et al. Avaliação do impacto da presença de sabor e odor no custo operacional de estações de tratamento de água. In: $23^{\circ}$ CONGRESSO BRASILEIRODEENGENHARIASANITÁRIAEAMBIENTAL. Anais Eletrônicos do $23^{\circ}$ Congresso Brasileiro de Engenharia Sanitária e Ambiental, Campo Grande, 2005. 